\title{
Enthusiasm for cancer screening in Great Britain: a general population survey
}

J Waller, K Osborne and J Wardle

Correction to: British Journal of Cancer (2015) 112, 562-566. doi:10.1038/bjc.2014.643; published online 23 December 2014

Updated online 26 May 2016: This article was originally published under a CC BY-NC-SA 4.0 license, but has now been made available under a CC BY 4.0 license. The PDF and HTML versions of the paper have been modified accordingly. (c) (i) This work is licensed under the Creative Commons Attribution 4.0 International License. To view a copy of this license, visit http://creativecommons.org/licenses/by/4.0/ 